\title{
Study on the Cultural Self-consciousness of Zhang-ke Jia
}

\section{Wenying Duan}

\author{
School of Chinese Literature, Datong University, Datong, Shanxi Province, China
}

Keywords: cultural self-consciousness, traditional culture, rational examination, cultural guidance

\begin{abstract}
Cultural self-consciousness means the self-awakening of culture. It is the need of the times in contemporary world, and a basic principle which modern humanistic intellectuals should follow. Zhang-ke Jia is a director of the new generation. He has insisted on taking lower-class people as narrative subjects in his movies for two decades. Through the using of dialects, his films present diversified Chinese local cultures. Born in Shanxi, Jia emphasizes the worship of Guan Yu (the battle saint) in his movies. He expresses the spirit of Guan Yu in various forms, in order to instruct people to follow morality and justice principles. The application of traditional Chinese operas in movies not only inherits the ancient art form, but also strengthens the narration of movies, and complies with his cultural self-consciousness principles.
\end{abstract}

\section{Cultural Self-consciousness}

The word "cultural self-consciousness" was first proposed in the fifth issue of Literary Contention in 1987. Ke-huan Lin, a dramatic critic wrote an article entitled Cultural Self-consciousness and Cultural Psychology. This article made comments on plays which won the National Excellent Play Award. Although the article was a dramatic review, it mentioned the cultural self-consciousness of playwrights, and reflected the cultural self-consciousness of Mr. Lin, who did not like to follow others and insisted on think calmly. Since then, articles on literature and social construction were published. These articles could be divided in two groups. One group concerned cultural self-consciousness embodied in literary creation, such as Cultural Self-consciousness of the Roots Tracing School written by Xiang Cai. The other group appealed on cultural self-consciousness of the whole nation in this cultural degradation society. For instance, personnel from the cultural circle of Zhejiang organized a seminar on cultural reality, and published the article titled Calling for Cultural Self-Consciousness of the Whole Society. All these articles pointed out that cultural self-consciousness was the principle which all literati should stick to, and mentioned that it was urgent and important to cultivate the cultural self-consciousness of the whole nation. But there was neither clear definition on cultural self-consciousness, nor feasible standards to carry out. Until 1997, on the second Senior Seminar on Social Anthropology organized by the Institute of Sociology and Anthropology of Peking University, Xiao-tong Fei made an in-depth analysis on "cultural self-consciousness", clearly defined cultural self-consciousness and explained how to practice cultural self-consciousness. Based his years of experience on social practice, and his teacher, Bronislaw Kalinowski's views on the difference between Chinese and westerners, Mr. Fei pointed out that, "cultural self-consciousness" required people living in a certain culture to have "self-knowledge" on their culture. They should understand the origin of their culture, as well as its formation process, characteristics and development trend. It did not mean "cultural return", nor advocated "Westernization" or "being assimilated". Although this concept was proposed to against the two extremist attitudes of "cultural redintegration" and "Westernization" held by Chinese people, it had a strategic global vision. Mr. Fei pointed out that the purpose of "self-knowledge" was to strengthen independent ability. It was necessary for any culture to adapt new environment and gain independent position. He also mentioned that the way to realize cultural self-consciousness was full of difficulties and hardships. How to implement "cultural self-consciousness" on that basis? Mr. Fei put forward to the strategy: "reserving differences between cultures, and making different cultures coexist peacefully, is the way we can realize universal harmony". [1] Since then, the concept of 
cultural self-consciousness has been vigorously promoted.

In the past twenty years, scholars have developed the concept of "cultural self-consciousness" with new interpretations from different perspectives, including political science, studies of Chinese ancient civilization, sociology, literature and other perspectives. However, these views can be roughly divided into three categories according to their connotations. Some scholars believe that, we should inherit fine Chinese traditions, since they are the root of our nation. Some hold that we should have self-knowledge and reflect ourselves frequently, in order to understand our strengths and shortcomings; we should also insist on seeking truth. Remaining scholars advocate on inheriting and reflecting ourselves, and trying to understand the culture of other countries on that basis, so as to grasp and guide the development trend of the Chinese nation. In this paper, Zhang-ke Jia's cultural self-consciousness is discussed on the basis of these interpretations.

\section{Cultural Self- consciousness of Zhang-ke Jia}

\subsection{The self-conscious of inheriting fine traditional culture.}

Zhang-ke Jia's inheritance of Chinese traditional culture is mainly embodied in three aspects: consciously inheritance of Guan Yu's spirit, consciously application of traditional Chinese operas, and consciously respect for local dialects.

The inheritance of Guan Yu's spirit in Zhang-ke Jia's movies is mainly manifested through external and internal ways. The explicit way highlights protagonists' worship of Guan Yu in movies. For instance, the miner Jianjun Liang's house was narrow, but there was still a table for Guan Yu's throne. Miners worship Guan Yu before went down to the well. For miners, the safety of underground work depended on the absolute loyalty and trust of other workers. Guan Yu, who represented loyalty and integrity in Chinese culture, was their spiritual pillar. In addition, in Zhang-ke Jia's films, young people and teenagers often walked on the street with Guan Yu's Green Dragon Crescent Blade, reflecting Shanxi people's respect and love for faithful and righteous persons, and the universal Guan $\mathrm{Yu}$ worship at grass-root level in Shanxi. Besides the external way, Zhang-ke Jia also presents the idea by the behaviors of protagonists in movies. In his life, Guan Yu was venerated by the world for his loyalty, faithfulness and courage. Although in Zhang-ke Jia's films, all heroes come from the bottom of society and have unsatisfactory defects, they all inherit the spirit of Guan Yu. For example, in the movie Xiao Wu, Xiao Wu earned his living by theft "skills", but he was absolutely loyal to his friends and always kept his promise. When he took the risk to get enough money for Xiao Yong's gift, Geng Sheng, the owner of a pharmacy was angry and asked, "Do you want to die?" Xiao Wu expressed that it was more important than his own life. Geng Sheng said Xiao Yong did not care much about his money. Xiao Wu replied, "We are different!" For Xiao Wu, Xiao Yong was a friend who grew up with him. Thus, it was not a matter of money; what matters was his commitment to his friends, and the friendship between buddies. Similarly, even facing townsmen or strangers, protagonists in Zhang-ke Jia's films always chose morality in front of money and morality. Shen Tao, in the movie of Mountains May Depart, heard that Liang $\mathrm{Zi}$ had difficulties. He was incumbent on giving Liang $\mathrm{Zi}$ money to treat disease. In the film of World, although Cheng Tai Sheng was unfaithful to love, he voluntarily took charge of the funeral of Er Gu-niang, a girl who came from his hometown. In Still Life, San-ming Han only met "bro Xiao Ma" for a few times, but he quietly buried "bro Xiao Ma" after his death. For them, they lift a finger to help others. But their behaviors all convey the moral sense of life, showing Guan Yu's spirit of "righteousness" and "faithfulness".

There are many traditional operas in Zhang-ke Jia's film, such as Kunqu Opera, Yue opera, Sichuan Opera, Jin opera, and Yangko with Umbrella. The application of traditional Chinese operas in movies not only inherits the ancient art form, but also strengthens the narration of movies. For example, in the movie 24 City, a more than four minutes excerpt from Shaoxing opera Dai-yu Lin Buries Fallen Flower Petals were selected, since the doom of Dai-yu was similar to that of the character Min-hua Gu. In the film A Touch Of Sin, an excerpt from Lin Chong Fled at Night was selected, because both Lin Chong and Da Hai were seeking revenge. The sad drum music of Jin opera indicated the inevitable tragedy of Da Hai's revenge. In the same film, excerpts from Jin opera The 
Story Of Sue San was also selected, since Sue San and Xiao Yu suffered from similar hardships and grievances. On the stage, Sue San withstood the extortive confession of royal court, crying for the suffering that she should not bear. Off the stage tears were full of Xiao Yu's eyes. She recalled that when she was young and beautiful, she killed a hooligan and was poisoned, though the hooligan was definitely guilty. At that time, Xiao Yu was released physically, but mentally, she was trapped into the nightmare forever.

Almost all characters in Zhang-ke Jia's films speak dialects. It is a conscious inheritance of traditional culture, and reflects his respect for dialect. As we all know, human beings are shaped by the land around them. All dialects experienced long time evolution in historical process. Embodied with extremely strong local colors and cultural emotions, they are the spiritual bond which connects ancestors and later generations. Nowadays, we are vigorously promoting mandarin to facilitate communication. The retention of dialects becomes more and more precious. Though the state provides strong support for dialect protection, the problem of missing dialects is becoming more and more urgent since large number of young people left their hometown. Zhang-ke Jia insists on using dialect for more than 20 years. It can be regarded as a conscious inheritance of dialect culture. Dialects also bring vitality to Zhang-ke Jia's movies, and make them special in the global movie industry. His movies have gained recognition both at home and abroad. The consciously inheritance of dialects helps Zhang-ke Jia to success. As Professor Bo-gong Shi from the Communication University of China expressed, "respect dialects in films means to respect folk wisdom, respect folk interest, and respect the law of art. This kind of respect is bound to inject films with more lasting vitality." [2]

\subsection{Insisting on seeking truth and rational examination.}

In the two decades of independent directing, Zhang-ke Jia insists on taking lower-class people as the narrative subject, striving to reflect their living environment and mental states. The primary problem for lower-class people is economic hardship. So their living environment is dark, noisy and disordered outside, while narrow and chaotic inside. This is the truth Zhang-ke Jia wants to express. People wondered why he did not record the bright side; Zhang-ke Jia replied that many people in China still lived in poverty. [3] Confusion and hopelessness of spirit comes together with economic hardship. It is another kind of truth the director want to express. Because of the realistic presentation of living environment in films, critics generally classify his movies as the Italy Neo-realism, which emphasizes the documentary character of "zero degree intervention". But through careful observation, differences between them are obvious. Italy Neo-realism style is more focused on the hardship and difficulty of underlying material. For instance, in Bicycle Thieves, the anxiety expressed in film is, how to live without bicycles. Zhang-ke Jia is more focused on characters' mental state of loss and helplessness. No matter Xiao Shan (Xiao Shan Goes Home), Xiao Wu (Xiao Wu) or Bin Bin (Unknown Pleasures), they worried more about "where I should go if I continue this kind of life". It is clear that Zhang-ke Jia has philosophical thinking. Zhang-ke Jia himself declared that "the purpose of all documentary methods is to describe the real world of characters' inner experience. We can hardly get close to reality. The meaning of movies is not to reach the level of truth. I pursue the sense of reality in movies rather than the pursuit of truth. Because I think reality is at aesthetic level, and it is the crisis of personal existence behind social problems." [4] Obviously, Zhang-ke Jia's reality is more about inner reality. These unsuccessful people form grass roots level are eager to success, while the bad deeds of "successful people" make them feel confused and hopeless. The crisis of this kind of confusion and desperation is not only limited in people who come from the bottom of society. In the movie Mountains May Depart, Jin-sheng Zhang was a millionaire. But he faced the situation of breaking up with his relatives. He had the right of using guns but he could not use them; he had beautiful house but lived a lonely life. If the crisis of lower-class people is caused by physical hardship, Jin-sheng Zhang's sorrow is obviously not related to money.

\subsection{Guiding the forms of movie.}

The importance of cultural guidance is an old issue. People usually mention the urgency of cultural guidance, but in real life, they always put economic benefits in the first place. Faced with that 
situation, Zhang-ke Jia also confused. Therefore, most of protagonists in his early works were trapped in the material prison. After the documentary Dong, although Zhang-ke Jia still paid attention to people from the bottom of society, his narrative style began to change. Painter Dong Liu received many honors but felt exhausted. He got away from the crowd, and sought for power of life in gravels and sands. Dong Liu's worship of life obviously influenced Zhang-ke Jia. In his next movie, Still Life, the director continued to show the sufferings of grass root people. But he showed his respect for those who sought to survive in ruins. [5] Only a few rich people can be seen in Jia Zhang-ke's films; almost all of them have bad endings. The earliest rich character is entrepreneur Xiao Yong in the movie Xiao Wu. Xiao Yong was treacherous, but respected by the world, which reflected the thorough erosion of money to common people. In A Touch Of Sin, there are two mine owners. One is Sheng-li Cui, who only cared money and was killed by the angry Da Hai in the end. The other was a Shanxi boss who lived a luxurious, dissipated life, but pretended to be literate and elegant. In Mountains May Depart, Jin-sheng Zhang fled from Australia, but then stayed in an empty house alone for the whole life. The ending of them are obviously mixed with Zhang-ke Jia's own subjective assumption, but it also shows his negation and satire to people who seek nothing but profits.

When economic matters almost occupy all of our lives, Zhang-ke Jia feels that the whole nation's culture is becoming powerless. So he stresses the importance of culture. He believes that the role of culture is to cultivate public to form the habit of thinking, so that the metal state of Chinese people will develop towards a healthy direction. But the reality is that, youth culture and rebellion culture are completely defeated by commercial values. [6] Thus, Zhang-ke Jia, through the hero of his movie Useless, presents a life style which almost excludes material life completely. The word "useless" comes from Chuang-tzu; it emphasizes "the meaning of useless". Fashion designer Ke Ma used this word to name his clothing brand, and used the most original manual sewing to against the mechanized garment production. Ke Ma believed that every thread of clothing had its own emotions and memories, and every dress had its own soul. This is exactly what Zhang-ke Jia wants to express. He wants to tell the world through the film that, in the pursuit of economic interests, we should also pay attention to our soul life.

\section{Conclusion}

"Humanistic intellectuals are not only participants and blind followers of history, but also more importantly, they are conscious historical reflectors and critics." [7] Zhang-ke Jia has directed films for twenty years. He once confused and angry, but he never followed the trend blindly. Under the impacts of commercialized movies, Jia has insisted on directing movies in his own ways, showing people, things, feelings and scenery which are not concerned by commercial films in China. When people challenged his movies by "seeking novelty", Zhang-ke Jia mourned for doubters and himself. Cultural self-consciousness is the self awakening of culture, while the premise of self awakening is to face reality. Without the truthful reflection of reality, cultural self-consciousness would become a castle in the air. What worries Zhang-ke Jia is that, if our culture fails to reflect the real predicament of our existence, how can we decide the path to follow? [8]

\section{References}

[1] X.T. Fei, Culture and Cultural Self-Consciousness, Qunyan Press, Beijing, 2016.

[2] B.G. Shi, Introduction to Folklore in Chinese Films, Communication University of China Press, Beijing, 2011.

[3] [8] [9] Z.K. Jia, J.H. Wan (eds.), Jia's Thought. Volume II, Movie Notes of Zhang-ke Jia from 2008 to 2016, Taihai Publishing House, Beijing, 2018.

[4] [6] Z.K. Jia, Jia's Thought from 1996 to 2008: Movie Notes of Zhang-ke Jia, Peking University Press, Beijing, 2009.

[5] W.Y. Duan, Transformation of narrative space and time in Zhang-ke Jia's movies, J. Movie 
Literature. 12 (2018).

[7] H. Yin Hong, Critical consciousness in the age of mass culture, J. Theoretical Studies In Literature and Art. 3 (1996). 